\title{
Qualifications of Food Science and Technology/Engineering professionals at the entrance in the job market
}

\author{
Virginia Giannou ${ }^{\mathrm{a}}$, Zoltan Lakner ${ }^{\mathrm{b}}$, Paola Pittia ${ }^{\mathrm{c}}$, Luis Mayor ${ }^{\mathrm{d}}$, Rui Costa $^{\mathrm{e}}$, \\ Cristina L. M. Silva ${ }^{\mathrm{f}}$, AND VAssiliki Oreopoulou ${ }^{\mathrm{a}^{*}}$ \\ ${ }^{a}$ National Technical University of Athens, School of Chemical Engineering, Laboratory of Food Chemistry and \\ Technology, Athens, Greece \\ ${ }^{\mathrm{b}}$ Corvinus University, Dept. of Food Economics, Budapest, Hungary \\ ${ }^{\mathrm{c}}$ Università degli Studi di Teramo, Facoltà di Bioscienze e Tecnologie Agroalimentari ed Ambientali, Teramo, \\ Italy \\ ${ }^{\mathrm{d}}$ Institute of Food Engineering for Development, Universitat Politecnica de Valencia, Valencia, Spain \\ ${ }^{\text {e }}$ Coimbra Higher School of Agriculture (ESAC), Polytechnic Institute of Coimbra (IPC), Coimbra, Portugal \\ ${ }^{\mathrm{f}}$ Centro de Biotecnologia e Química Fina - Laboratório Associado, Escola Superior de Biotecnologia, \\ Universidade Católica Portuguesa/Porto, Portugal \\ ${ }^{*}$ Corresponding author \\ vasor@chemeng.ntua.gr \\ TEL: +302107723166 \\ FAX: +302107723163
}

Received: 24 July 2014; Published online: 18 October 2015

Invited paper from the $3^{\text {rd }}$ International ISEKI_Food Conference - ISEKI_Food 2014 - Bridging Training and Research for Industry and the Wider Community - Food Science and Technology Excellence for a Sustainable Bioeconomy

\begin{abstract}
The qualifications of Food Science and Technology/Engineering (FST/E) professionals were examined by a web-based survey conducted in 15 countries (14 EU and Turkey). The analysis of the responses showed that $65 \%$ of the respondents had a higher education (HE) degree (BSc 29\%, MSc $28 \%$, and $\mathrm{PhD} 8 \%$ ), and $20 \%$ carried out extracurricular training before entering in the job market. The main fields of study were Food Science and Technology/Engineering, followed by Agriculture, Nutrition and Health, Safety/Hygiene, and Chemical Engineering in all three levels of HE degrees. Differences in the level of degree between genders were not observed, although a higher percentage of female respondents ( $36 \%$ of all female respondents) reported no higher qualification degree, compared to male respondents ( $33 \%$ of all male respondents). On the contrary, female respondents prevailed in extracurricular studies, compared to male ones. Gender, however, was a differentiating factor as far as the field of studies was concerned with female respondents prevailing in Nutrition and Health and male in Agriculture.

A considerable percentage of the respondents acquired either a HE degree or had extracurricular training while working in the $1^{\text {st }}$ job. Extracurricular training both before entering the job market and during work at the $1^{\text {st }}$ workplace comprised mainly the topics Safety and Hygiene, Management, followed by Sensory Science, FST/E and Nutrition and Health. In addition, Marketing Science/Consumer Behaviour was also one of the main topics of company or other training during work at the $1^{\text {st }}$ workplace.
\end{abstract}

Keywords: Education; Training; Job Market; Higher education degrees; Professional qualifications 


\section{Introduction}

Higher Education study programmes in the field of Food Science, Engineering and Technology present great variations in EU countries. Several countries, i.e. Spain, Greece and Belgium, have historically covered these disciplines with general curricula providing degrees in Agriculture, Chemistry or Chemical Engineering. In other countries, universities introduced and developed faculties and curricula providing specific degrees in Food Science, Food Engineering and/or Food Technology. Moreover, in more recent times, disciplines like Nutrition, Safety and Hygiene, etc., have been included in some Food study programmes as well as in the corresponding degree title for the graduates. These changes are a result of the demands of the food sector, and especially of the Food and Drink (F\&D) industry to employ graduates who are highly qualified in all the specific topics related to food.

The F\&D industry is the largest manufacturing sector in the EU, with a share in turnover of $14.6 \%$. The number of F\&D enterprises in the EU amount to around three hundred thousand; they employ more than four million people, making the F\&D industry the leading employer in the EU with a share of $15.5 \%$ (Food Drink Europe, 2014). While the quality and safety of food products remains a main issue, the demand for highly qualified personnel arises from the need of the EU F\&D industry to implement innovation and increase competitiveness against emerging economies (Jassi et al., 2013). This has been also shown by the study of Flynn, Wahnstrom, Popa, Ruiz-Bejarano, and Quintas (2013) who carried out a survey to identify the ideal skills of the Food Science and Technology professionals from the employers' point of view, which revealed that they ranked "Product Development" in the top position.

However, the food sector employs professionals with diverse studies, level of education and/or HE degrees with different knowledge, skills and expertise, based on the general assumption that other science based study programmes (e.g. engineering, chemistry, biology) can also provide graduates with sufficient knowledge and skills in food processing, characterization and quality control, even if supplementary food specific knowledge is needed, and can be obtained by training. On the other hand, the main characteristic of the FST/E study programmes is the educational approach based on an integrated multidisciplinarity that allows graduates to enter in the job market with the appropriate knowledge and technical skills, including food quality and safety, food analysis, processing and engineering as well as nutrition.

The identification of the qualifications of employees when entering the workplace could thus offer important information by correlating them with current and future needs in terms of knowledge and skills to improve their study and professional career and meet the challenges of F\&D industry. In this framework, the TRACK_FAST: Training Requirements and Careers for Knowledgebased Food Science and Technology in Europe (www.trackfast.eu) project was undertaken to identify the training and career requirements of future European Food science and technology (FST) professionals, and implement a European strategy to recruit the next generation of FST leaders. "Food science and technology professionals" means those professionals working in industry, government bodies, research and education institutions and any other service, whose core activity is related with FST.

The present paper will present and discuss the results of a survey conducted under the TRACK_FAST project about the qualifications of the FST professionals at the entrance of the job market and how it affects their placement in work, in terms of the area of placement (industry, government bodies, research and education institutions, and any other service) and sector of activity.

The survey was conducted through a web-based questionnaire that was distributed within $15 \mathrm{EU}$ and associated countries to FST professionals in the food sector.

\section{Methodology}

\subsection{Questionnaire structure}

A "check-box" type questionnaire was prepared in order to enable respondents to answer questions by simply choosing the option they agreed 
with. It was composed of four main parts, as described by Oreopoulou et al. (2015) and included, among others, questions to achieve information about the:

- higher education qualifications obtained before entering the $1^{\text {st }}$ workplace; in particular the scientific field (Agriculture, Chemistry, Chemical Engineering, Environmental Engineering, Food Science and Technology/Engineering, Nutrition and Health, Safety and Hygiene, Sensory Science, Economics, Marketing, Management, Other) and the degree level (BSc, MSc, $\mathrm{PhD}$ ),

- extracurricular qualifications obtained before entering the $1^{\text {st }}$ workplace,

- higher education qualifications obtained during working at the $1^{\text {st }}$ workplace,

- company or other extracurricular training obtained during working at the $1^{\text {st }}$ workplace,

- area of employment at the $1^{\text {st }}$ workplace (industry, including food processing, retail and consultancy; research and education institutions; governmental agencies; or other including food service and distribution), and

- sector of activity at the $1^{\text {st }}$ workplace (research \& development; quality control; production; logistics/distribution; consumer/marketing studies; financial/administrative; legal/legislative; technical/commercial; environment/safety; other).

In addition, the questionnaire included questions to identify the basic demographic characteristics of the respondents, as well as their current area of employment.

\subsection{Survey procedure}

The questionnaire was distributed through the SurveyMonkey ${ }^{\circledR}$ web-based survey tool in Austria, Belgium, England, France, Germany, Greece, Hungary, Italy, Lithuania, Portugal, Romania, Slovenia, Spain, Sweden and Turkey, translated into the corresponding native languages. The invitation to fill in the webbased questionnaire was distributed through the TRACK_FAST partners to individuals, professional associations and the food industry by email as well as by using innovative web based tools including social and professional networks (Facebook, LinkedIn) in the period February 2011 to May 2012.

\subsection{Statistical Analysis of results}

Results of the survey were analysed by different subroutines of SPSS software. To obtain a general overview the standard descriptive statistics (e.g. frequency tables, average), analysis of variance and multivariable methods were used. Duncan's multiple range test was used to define statistically significant differences at $\mathrm{p}<0.05$.

\section{Results and Discussion}

\subsection{Profile of the respondents}

During the survey, 3007 questionnaires were filled in, partially or completely. In some cases, respondents did not answer to all questions including those with the information on country, gender, and/or age. Therefore, the analysis of data was occasionally based on the effective number of respondents that answered the specific question. Variations were also observed in the number of respondents per country. The number of answers was higher in countries with regulated professions (Italy and Turkey, with 610 and 477 respondents, respectively) and in Spain (410), where, thanks to the collaboration in the dissemination of the survey through professional bodies and social networks, it was also very effective. The number of answers from Greece (147), Hungary (212), Lithuania (79), Portugal (309), Slovenia (98), and Sweden (106) was also considered satisfactory considering the ratio of the No answer/No employees (Oreopoulou et al., 2015). Therefore, the survey was regarded as providing a satisfactory image of food professionals in most of the countries surveyed, even though some countries with a large food industry (e.g. Germany, France and UK) were not significantly rep-

\begin{tabular}{l|l|l|l} 
IJFS | October 2015 | Volume 4 & pages 173-187
\end{tabular} 
resented.

Considering gender and age, the majority of the respondents of the survey were women $(60 \%$ female respondents versus $40 \%$ male), while younger generations were over-represented (Figure 1) as almost $60 \%$ of the survey sample was under 35 years. This can be explained by the fact that computer-literacy is higher among the younger generations of professionals, and they are more likely to respond to the questions of such type of survey; additionally, the older generation of food professionals could have limited time or be less attracted to respond to the questionnaires due to their likely more demanding job positions. thus, due to the age profile of the respondents, most of the collected information was related to the last 10-15 years and reflected the more recent and current status of education degree and entrance to work.

\subsection{Qualifications obtained before entering the job market}

\section{Scientific field and degree of qualification}

Respondents were asked to indicate whether they had obtained a higher education degree (BSc, MSc, or PhD) and/or extracurricular training before entering their $1^{\text {st }}$ workplace along with the scientific field of their degree by selecting it from a list included in the questionnaire. In case that the respondent reported more than one level of degree, the analysis of the data was based on the highest selected level. The results of higher education degrees and extracurricular training are presented in Figure 2. The $65 \%$ of the respondents stated they had a higher education degree, as indicated by the cumulative higher degree column, being $29 \%$ with BSc, $28 \% \mathrm{MSc}$, and $8 \%$ with $\mathrm{PhD}$ degree (Oreopoulou et al., 2015; Mayor et al., 2015). The high percentage of $\mathrm{PhD}$ holders could be partially attributed to the survey procedure, i.e. the invitation to complete the questionnaire was sent mainly by people working in higher education institutions, who could have $\mathrm{PhD}$ graduates in their professional contacts and collaborators. It was also observed that $20 \%$ of total respondents had carried out at least one extracurricular activity (internships, courses) before entering work. Within those respondents who carried out extracurricular activities, the average number of activities per respondent was 2.2 .

The main fields of study in all three levels of higher education degrees were "Food Science and Technology/Engineering (FST/E)", followed by "Agriculture", "Nutrition and Health", "Safety and Hygiene", and "Chemical Engineering". To better elaborate the results, the scientific fields were grouped in six categories: 1="Agriculture", 2="Chem./Chem. Eng.", including "Chemistry", "Chemical Engineering" and "Environmental Engineering" (the latter having been stated by very few respondents), $3=$ "Food Science \& Technology/Engineering (FST/E)", 4="FST related", including "Nutrition and Health", "Safety and Hygiene" and "Sensory Science", $5=$ "Economics/Marketing/Management", $6=$ "Other" (few respondents stated a specification such as "Food Microbiology" and "Biochemistry/Biotechnology"). The results are presented in Figure 3 and indicate that more than $40 \%$ of the respondents gave "FST/E" for their BSc or MSc degree. Differences were observed in $\mathrm{PhD}$ degree, where a lower percentage of respondents achieved it in "FST/E" compared to BSc and MSc degrees, while the rest carried out "FST related" studies, "Agriculture" or "Chem./Chem. Eng.". "Other" fields (including "Food Production", "Food Microbiology" and "Biochemistry", as specified by the respondents) were also mentioned by a higher percentage for $\mathrm{PhD}$ studies, compared to BSc and MSc.

Interesting differences were observed among countries in the most popular fields of study. Italy and Turkey presented the highest percentage of respondents $(72.5 \%$ and $51.8 \%$, respectively) with a higher education degree in "FST/E", while the lowest percentages were from Spain (21.8\%) and Sweden (21.5\%) with "Agriculture" (given by $38.9 \%$ of Spanish respondents), and "Chemistry" (given by $26.2 \%$ of Swedish respondents), being, respectively, the most frequent study fields in these latter countries.

Similarly, in Greece and Belgium higher ed- 


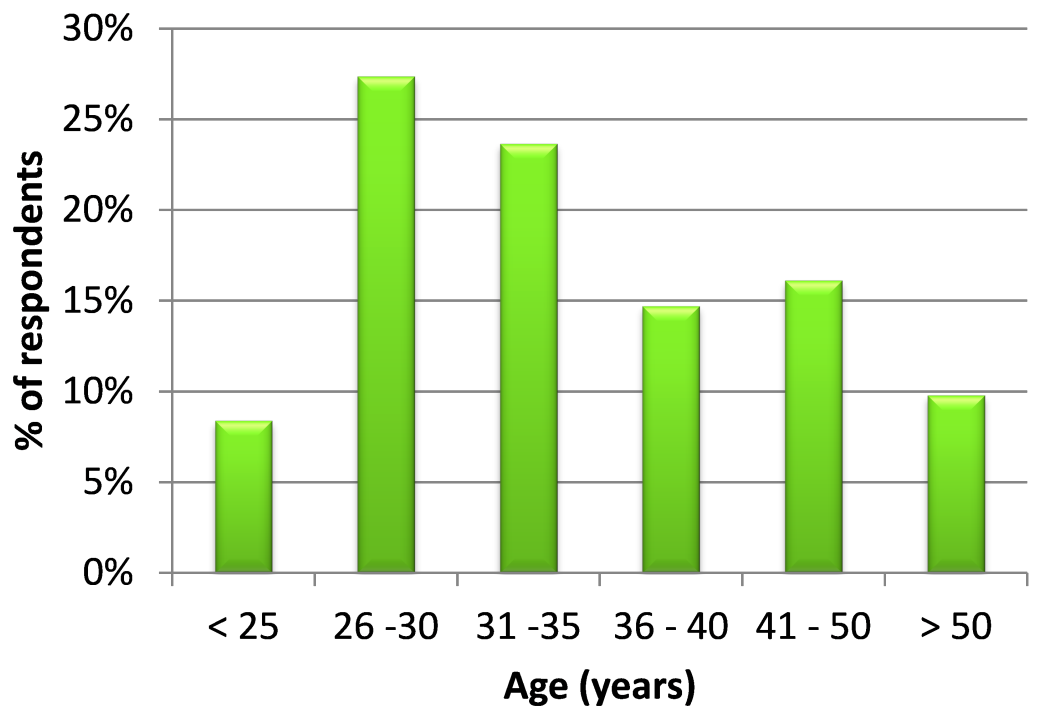

Figure 1: Age distribution of respondents

ucation qualifications other than "FST/E" dominated (i.e. "Chemistry", "Agriculture" and "Chemical Engineering"), while in Lithuania, Portugal, Slovenia, Germany, France and Hungary, "FST/E" was the predominant higher education degree of the respondents. These differences reflected differences in higher education structure among countries, with some of them, like Italy, Portugal, etc., having established degrees in "Food Science/Technology or Engineering" for a long time, while others (e.g. Spain and Greece) include food-related courses in their "Agricultural" or "Chemistry/Chemical Engineering" programme degrees and only recently have introduced and developed "Food"-oriented curricula. Additionally, the regulation of a food profession by national laws, like "Food Technologist" in Italy and "Food Engineer" in Turkey, requires the respective degree from candidates to be enrolled in the specific profession, and might be considered one of the main reasons why the "FST/E" degree dominates in these countries.

The most important fields of extracurricular training were quite different when compared with higher education degrees. They comprised mainly the topics "Safety and Hygiene" (18.6\%), and "Management" (including quality and safety) (17.9\%), followed by "Sensory Science" (10.7\%), "FST/E" (9.9\%), and "Nutrition and Health" (9.1\%).

\section{Effect of gender}

Differences in the level of degree between the genders were not observed, although a higher percentage of female respondents $(36 \%$ of all females) reported to have started work without a higher education degree, compared to the male ones (33\% of all males). On the contrary, a higher percentage of female respondents $(21.7 \%)$ carried out extracurricular training, compared to the male ones $(17.6 \%)$.

Gender was also a differentiating factor with respect to the field of study, with the exception of "FST/E", with female respondents prevailing in "FST related" studies, in particular "Nutrition and Health", and males in "Agriculture" (Figure $4)$.

\section{Effect of age}

The field of higher education studies was also correlated with the age of the respondents. A higher percentage of respondents above 50 years

\begin{tabular}{l|l|l|l} 
IJFS | October 2015 | Volume 4 & pages 173-187
\end{tabular} 


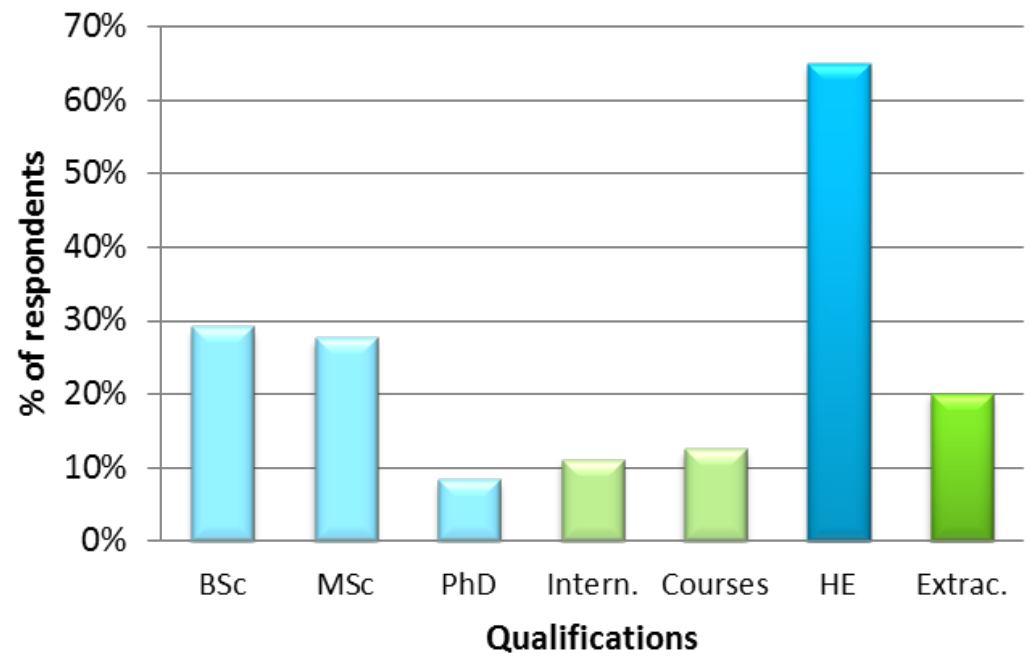

Figure 2: Higher education degrees and extracurricular training before entering the $1^{\text {st }}$ workplace (Intern.=Internships, $\mathrm{HE}=$ Higher education degrees, Extrac.=Extracurricular training)

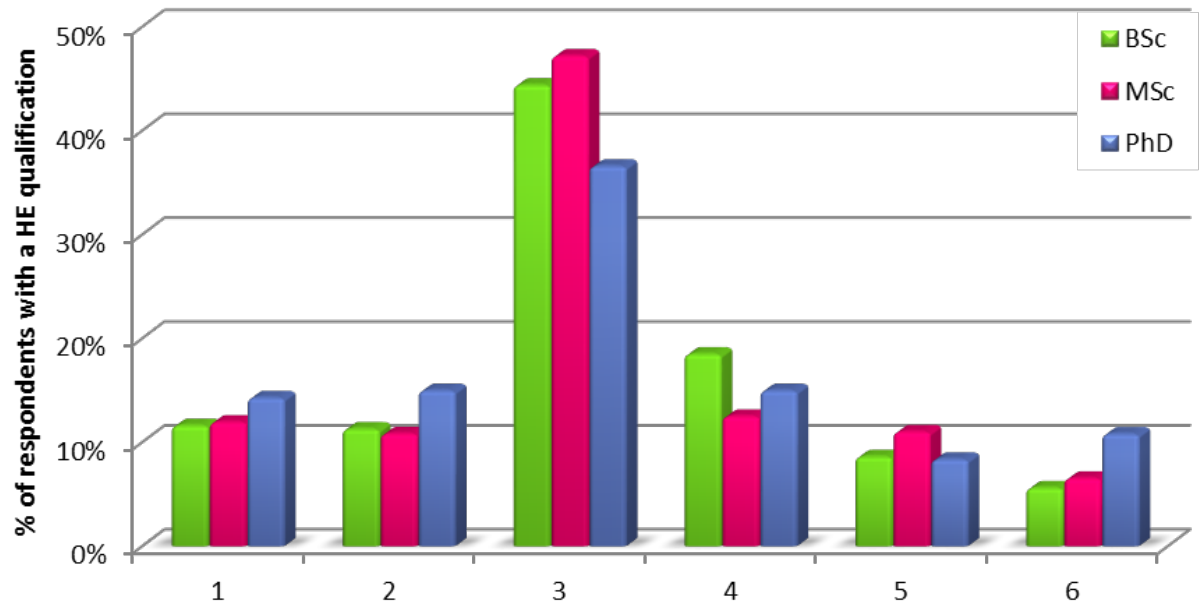

Figure 3: Main field of study and level of higher education (HE) degree of respondents before entering the $1^{\text {st }}$ workplace (1= "Agriculture", 2= "Chem./Chem.Eng.", 3="Food Science \& Technology/Engineering", $4=$ "FST related", $5=$ "Economics/Marketing/Management", 6="Other") 


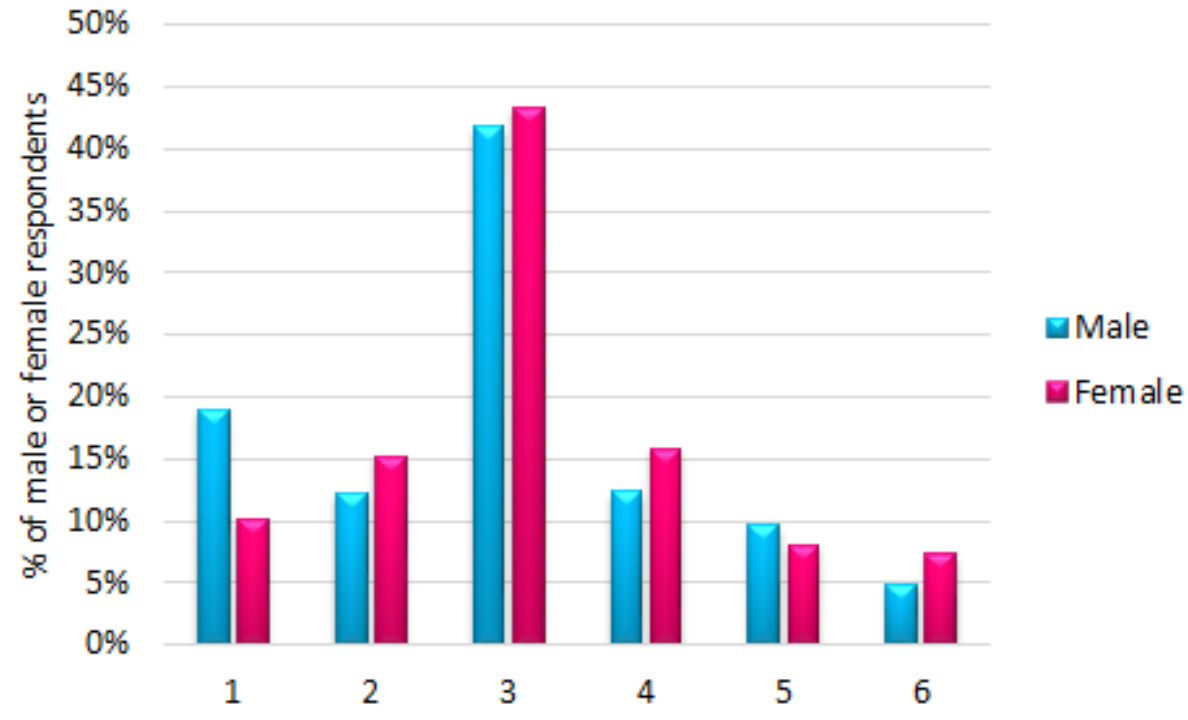

Figure 4: Fields of higher education study before entering the $1^{\text {st }}$ workplace: effect of gender $(1=$ "Agriculture", 2="Chem./Chem. Eng.", 3="Food Science \& Technology/Engineering", 4="FST related", $5=$ "Economics/Marketing/Management", 6="Other")

of age obtained higher education degrees (especially BSc) in basic scientific fields, like "Chemistry", "Chemical Engineering", and "Agriculture", while this percentage decreased in younger generations and was progressively replaced by degrees in "FST/E" or "FST related" studies (Figure 5). This result reflected changes in the higher education curricula and the introduction of "FST/E" studies in EU universities. On the other hand, responses showed that the extracurricular training of the younger generation of respondents was more oriented towards "FST related" areas.

In addition, the level of degree depended on the age of the respondents, with a higher percentage of younger respondents having acquired a BSc or MSc, and older respondents a PhD degree (Figure 6). Taking into account the pool of respondents, the percentage of individuals possessing a $\mathrm{PhD}$ degree decreased as the age decreased. This fact might reflect differences among generations in their attitude towards higher levels of university degrees, since $\mathrm{PhD}$ programmes are in general considered more science-research oriented than profession/industry oriented. This result, however, was not in agreement with the growing number of science doctorates earned each year in countries that are members of the Organisation for Economic Co-operation and Development (OECD) (Cyranoski, Gilbert, Ledford, Nayar, \& Yahia, 2011). In particular, an increase of nearly $40 \%$ between 1998 and 2008 was observed in OECD members, but the European countries presented big variations with Portugal and Italy showing an average annual growth higher than 10\%, while Germany and France were found at the bottom with no increase (Auriol, 2010). However, the increase of the percentage of PhD holders with age (Figure 6) could be attributed to the long education and late arrival on the labour market of the $\mathrm{PhD}$ holders that skewed the age structure of employed $\mathrm{PhD}$ holders towards the upper age categories (Auriol, 2010). 
$180 \mid$ Giannou et al.

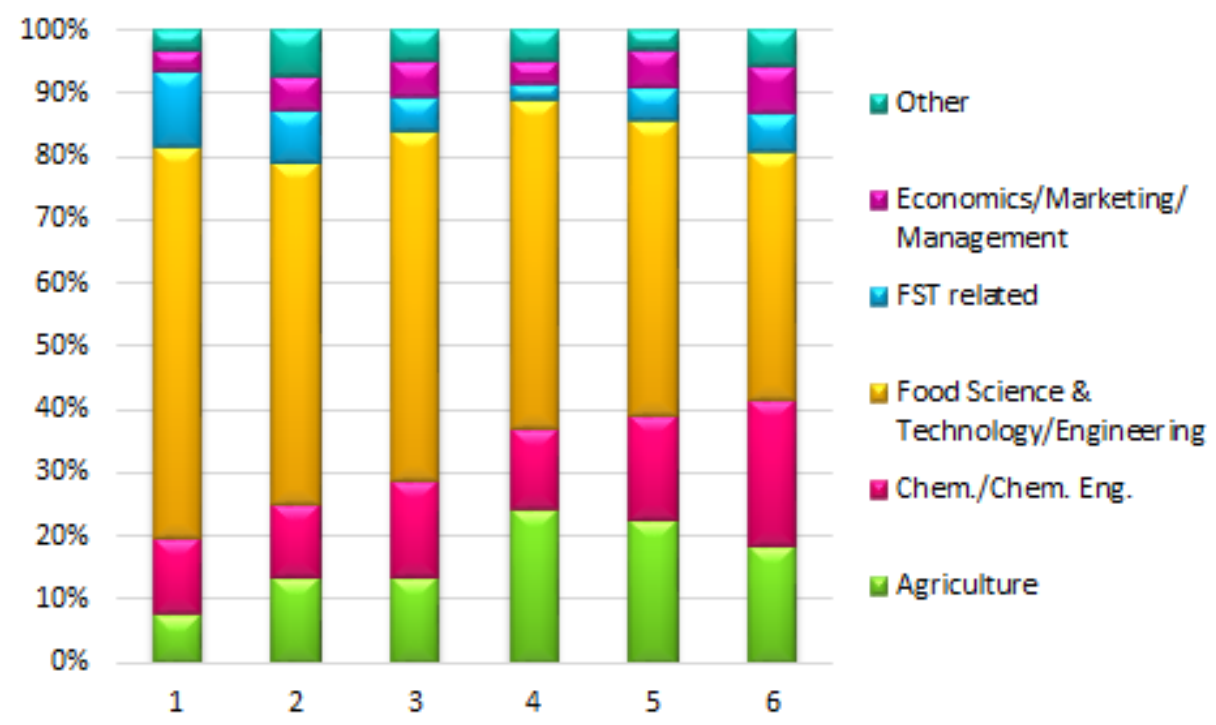

Figure 5: Effect of the age of the respondents on the fields of higher education study before entering the $1^{\text {st }}$ workplace $(1=<25,2=26-30,3=31-35,4=36-40,5=41-50,6=>50$ years old $)$

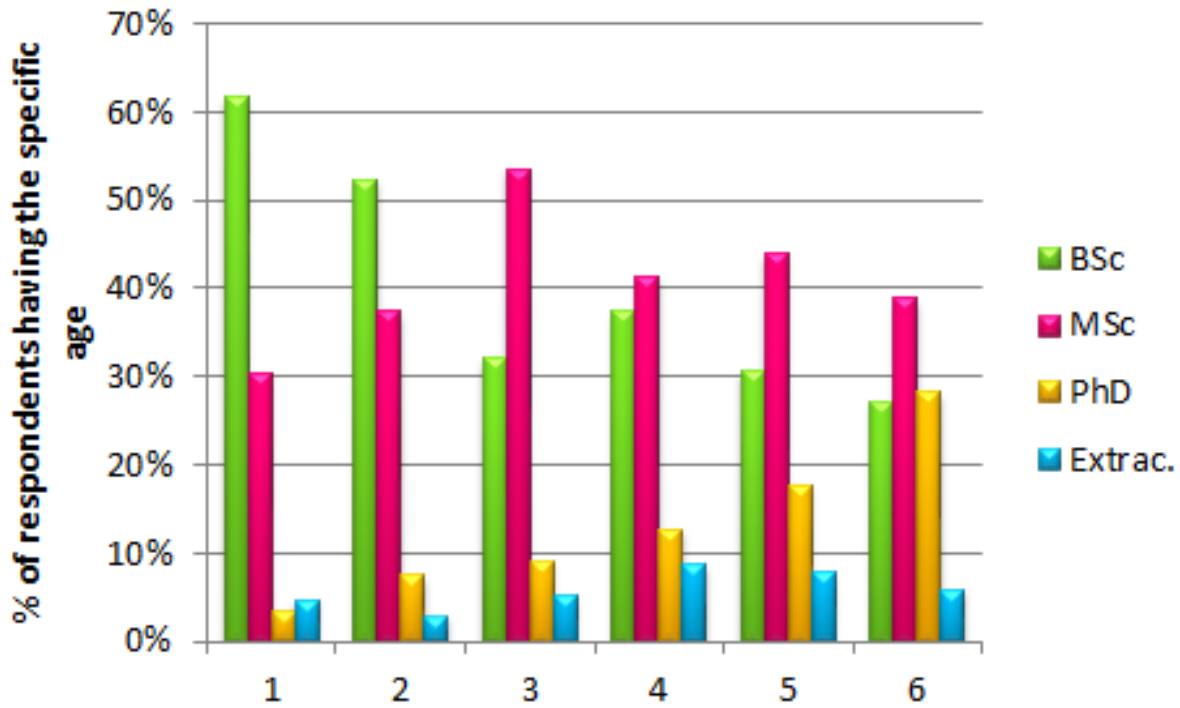

Figure 6: Effect of the age of the respondents on the level of higher education degrees $(1=<25,2=26$ - 30 , $3=31-35,4=36-40,5=41-50,6=>50$ years old) 


\subsection{Qualifications obtained during $1^{s t}$ job}

A considerable percentage of the respondents $(14 \%)$ indicated that they had acquired a higher education degree and/or extracurricular training $(23 \%)$ while working in their $1^{\text {st }}$ job. Figure 7 presents the differences in the level of higher education degrees obtained in the $1^{\text {st }}$ job, depending on the education level of the FST professionals before entering work. As can be seen, most of the respondents continued their studies to obtain the next level of the higher degree that they already possessed. However, $9 \%$ of those with a $\mathrm{HE}$ degree obtained a $2^{\text {nd }} \mathrm{BSc}$ degree in another scientific field, while $8 \%$ of respondents without a HE degree obtained their first BSc degree.

The scientific field of the higher education degree obtained during $1^{\text {st }}$ job, as related to that obtained before entering work, is presented in Table 1. Respondents who had obtained a higher degree in "FST/E", "Chemical Engineering", "Economic Sciences", and "Agriculture" before work preferred to continue their studies in the same field. The "FST/E" qualification was ranked second, being selected as likely to supplement the missing technical skills of the specific field of activity. In particular, those respondents who had at entry to their $1^{\text {st }}$ workplace a qualification in "FST/E", achieved further qualifications in "Management", "Nutrition and Health", "Safety and Hygiene" as well as other food-related disciplines. These subjects may have been of interest both so that the respondents could undertake a more specialised career and to supplement missed technical knowledge. However, respondents with a background in "FST related" studies, "Marketing Science", "Management", and "Chemistry" tended to oscillate between "FST/E" and "Marketing" /"Management" studies during work (Table 1).

Extracurricular training during work at the $1^{\text {st }}$ workplace comprised mainly the topics "Safety and Hygiene", and "Management", followed by "Sensory Science", "FST/E", and "Nutrition and Health", similar to what was reported before entering the job market (Figure 8). In addition, "Marketing Science/Consumer Behaviour" was also one of the main interests of company or other training during work at the $1^{\text {st }}$ workplace. It is interesting to note that extracurricular training was mainly reported by respondents entering the job with a BSc or an MSc degree (approximately $10 \%$ of each category). Within those respondents who carried out training activities, more than one training activity was given by most respondents with an average of 2.5 activities/respondent.

Extracurricular training was undertaken either inside the company $(60 \%)$ or by following external courses (40\%). Company training was mostly reported by respondents working in large companies (more than 250 employees). The main topics in both company and external training were "Management" and the "Safety and Hygiene". This result may highlight the importance given by both the employees and the employers to specific technical skills that are not likely to be fully developed during higher education, but recognised as determinant in the roles covered by the respondents as well as for their career progression. "Safety and Hygiene" training could be associated with the need for continuous updating due to the new regulations issued at national and EU level associated with knowledge generated by research and/or with new outbreaks of foodborne illnesses.

\subsection{Area of employment and sector of activity}

The majority of the respondents (56\%) gave their $1^{\text {st }}$ area of employment as "Industry" (including retailing and consultancy), while $17 \%$ were employed in "Research and Education Institutions", $9 \%$ in "Governmental Agencies", and 18\% in "Other" (including food service and distribution). These results indicated that industry is the main area where FST professionals find jobs, as expected; however, more than $40 \%$ of them began their professional career in other areas, mainly in research and education institutions. Shewfelt (2012) also noticed such high number of food scientists employed in research and education institutions compared to other areas. However, the high percentage of the respondents starting work in research/education insti- 
182 | Giannou et al.

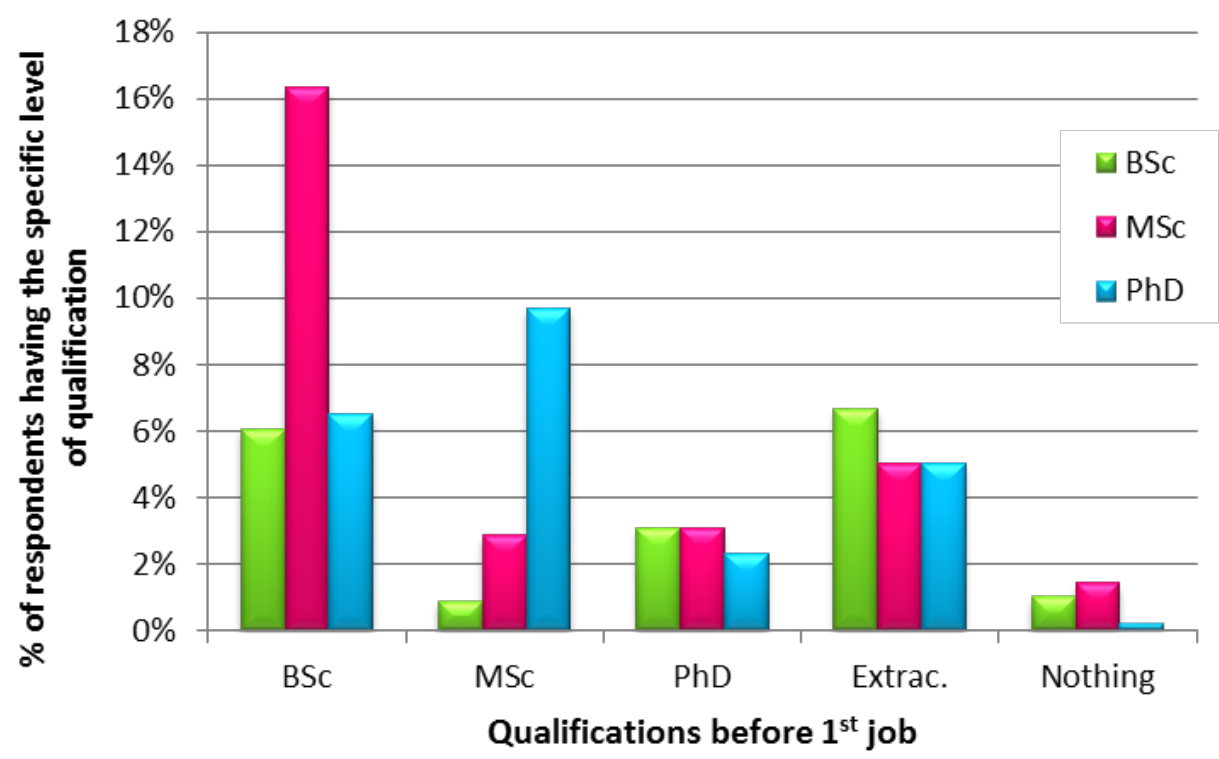

Figure 7: Differences in the level of higher education (HE) degrees obtained in the $1^{\text {st }}$ first job, depending on the education level of the FST professionals before entering work

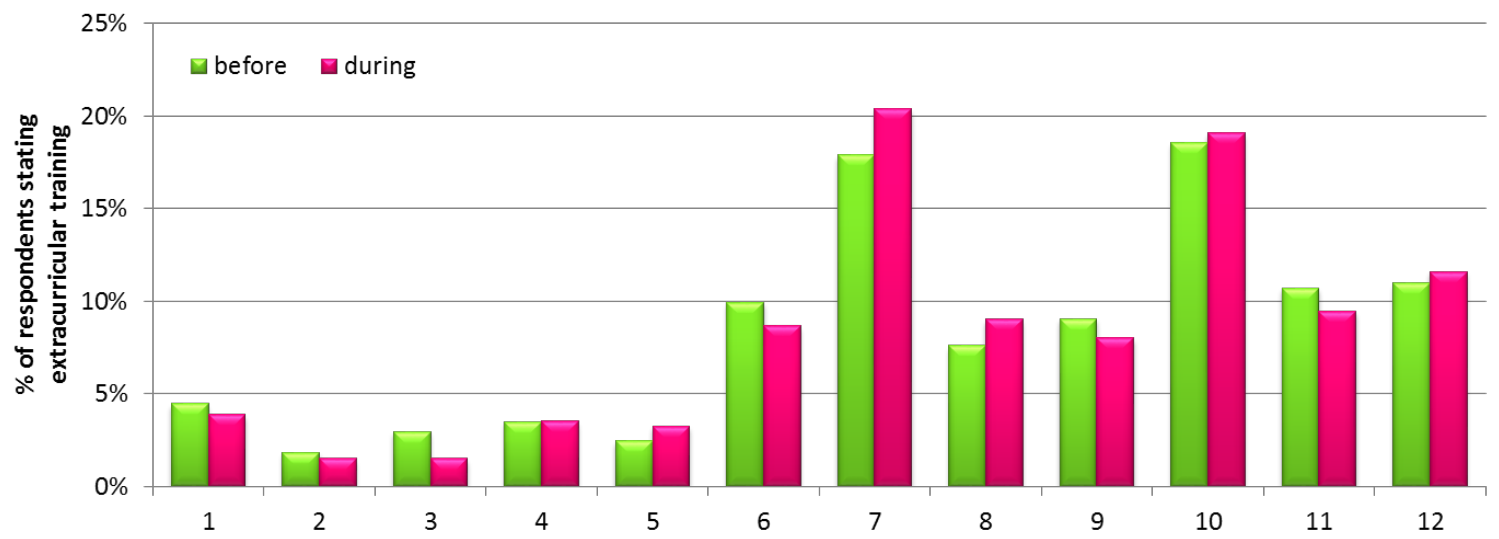

Figure 8: Extracurricular training before and during work at the $1^{\text {st }}$ workplace $(1=$ Agriculture, $2=$ Chemistry, $3=$ Chemical engineering, $4=$ Economic sciences, $5=$ Environmental engineering, $6=$ Food Science \& Technology/Engineering, $7=$ Management, $8=$ Marketing science $/$ Consumer behaviour, $9=$ Nutrition and health, $10=$ Safety and hygiene, $11=$ Sensory science, $12=$ Other) 


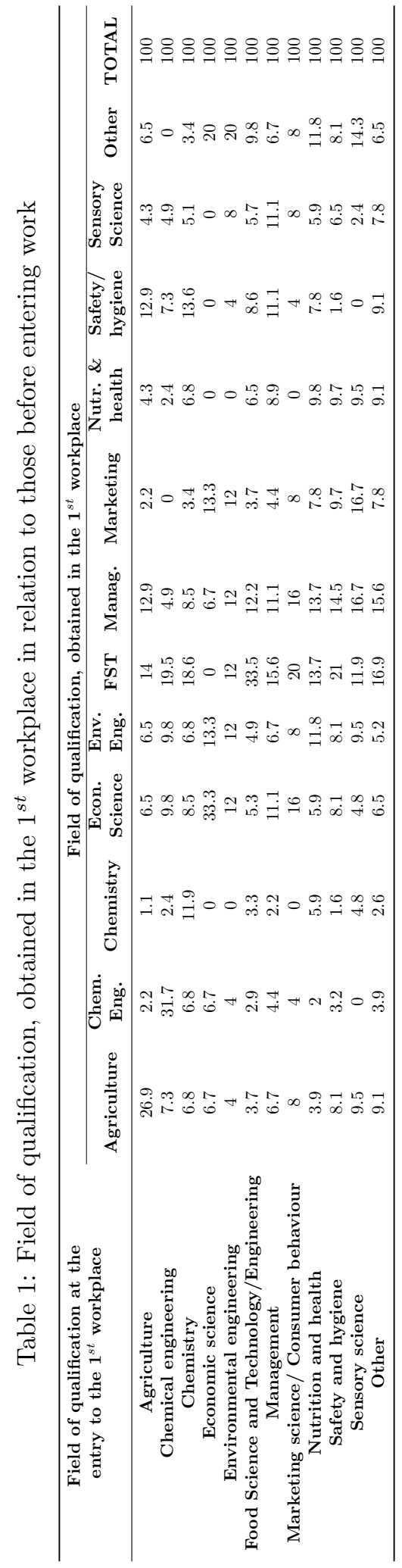


tutions in our survey could be also attributed to the high percentage of $\mathrm{PhD}$ holders participating in the survey. The study of Auriol (2010) indicated that the main area of employment for doctoral graduates in almost all European countries is in higher education followed by research.

\section{Effect of qualification}

The field of qualification affected both the area of employment and sector of activity. Most of the respondents found their $1^{\text {st }}$ job in the "Industry" (including food processing, retail and consultancy), independently of their qualification (Figure 9). However, among respondents with qualifications in the "FST related" ("Nutrition and Health", "Safety and Hygiene", "Sensory Sciences"), and in "Other" fields, a high percentage entered work in "Other" areas, including food service and distribution. This result indicates that these specific, food-related qualifications were preferred by the employers of the food service, distribution and "Other" area. On the other hand, the percentage of those holding degrees in "Agriculture", "Chemistry", and "Chemical Engineering" who gave "Research/Education" as their area of employment was higher than respondents qualified in other scientific fields. This may be related to the strong background and recognition of the basic sciences in the area of education and research in most European countries. It is interesting also to note the higher percentage of employment in "Governmental Agencies" among respondents qualified in "Other" fields, compared to all other respondents.

Regarding the sector of activity (Table 2), most respondents $(28.1 \%)$ stated "Research and Development" , followed by "Quality Control" (26.1\%) and "Production" (19.1\%). However, it was interesting to note that respondents with "Chem./Chem. Eng." studies found their professional career mostly in the "Research and Development", and the "Quality Control" sector (42.3\% and $27.9 \%$, respectively) and with a lower percentage in "Production" (13\%). Respondents with qualifications in "Agriculture" found a job in "Research and Development" (34.7\%) instead of "Production" (10.8\%). On the contrary, "Production" was given by a noticeably higher per- centage of respondents qualified in "FST/E" or "FST related" fields. The higher percentage of "Research and Development" activity reported by respondents with studies in "Chem./Chem. Eng." or "Agriculture" could be partially attributed to the higher percentage of employment in the "Research/Education" area. However, as most of the respondents were employed in "Industry", the results of Table 2 indicated that the European F\&D industry prefers employees with "FST/E" or "FST related" studies for "Production".

\section{Effect of gender}

As far as the effect of gender on the area of employment was concerned, more male respondents were employed in "Industry" (54\% vs. $46 \%$ for women), while female respondents were predominant in "Research/Education institutions" ( $58.7 \%$ vs. $41.3 \%$ for men) and "Governmental agencies" ( $55 \%$ vs. $44 \%$ for men) based on normalized data. With respect to the sector of activity, there were significant differences between male and female respondents in "Logistics/distribution" ( $77.5 \%$ vs. $22.5 \%$ for women), "Production" (68.1\% vs. 31.9\%), "Technical/commercial" (67.4\% vs. $32.6 \%)$ and "Environmental/safety" (61.9\% vs. $38.1 \%)$. Conversely, more female respondents indicated that they were in "Quality control" (63.1\% vs. $36.9 \%)$ and "Consumer/Marketing studies" (53\% vs. $47 \%)$.

\section{Conclusions}

The majority of FST professionals who started work in the industry appeared to be well qualified and had a high level of education. A considerable proportion obtained additional qualifications during work. Younger generations were mostly oriented to "FST/E" or "FST related" studies that have been introduced in many European Universities. Basic scientific fields, like "Chemistry", "Chemical Engineering", and "Agriculture" were more often reported by the older generation of professionals, compared to the younger ones, but it should also be noted that these fields (especially "Agriculture") have 


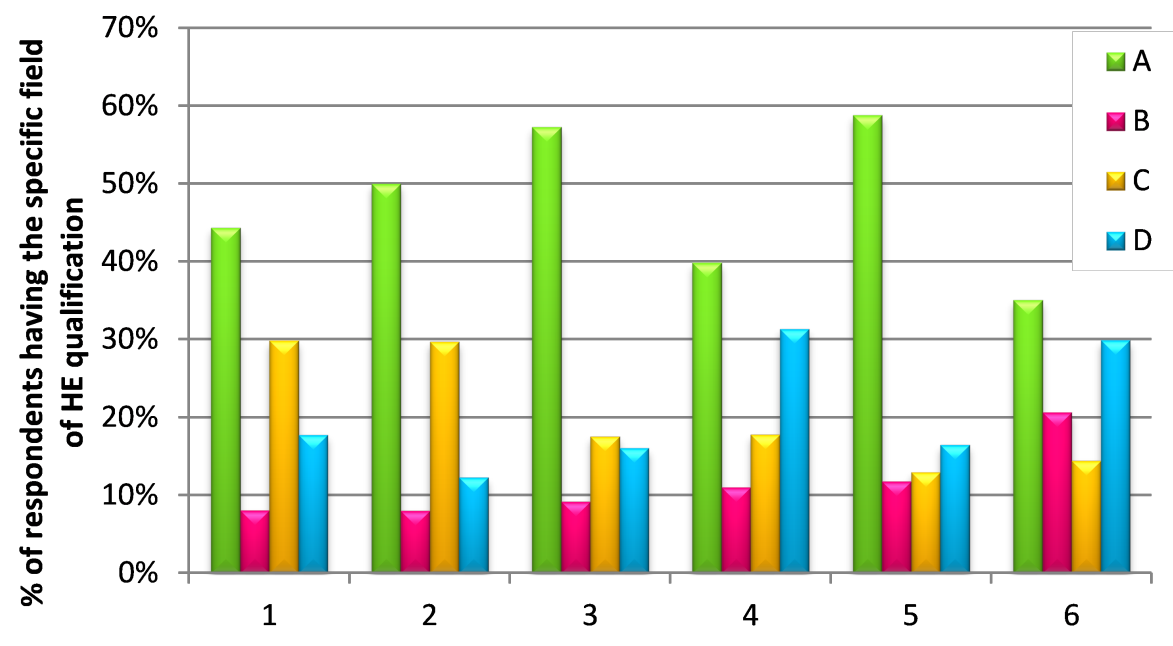

Figure 9: Effect of the field of higher education (HE) qualification of respondents on their area of employment $(\mathrm{A}=$ Industry, including food processing, retail and consultancy, $\mathrm{B}=$ Governmental agencies, $\mathrm{C}=$ Research/education institutions, $\mathrm{D}=$ Other, including food service and food distribution, and 1="Agriculture", 2="Chem./Chem. Eng.", 3="Food Science \& Technology/Engineering", 4="FST related", 5="Economics/Marketing/Management", 6="Other")

Table 2: Effect of the field of qualification of respondents on their sector of activity

\begin{tabular}{|c|c|c|c|c|c|c|c|}
\hline \multirow[b]{2}{*}{ Sector of activity } & \multirow[b]{2}{*}{$\begin{array}{c}(\%) \\
\text { of total }\end{array}$} & \multicolumn{6}{|c|}{$\begin{array}{l}\text { Qualification (\% of the respondents } \\
\text { having the specific activity type) }\end{array}$} \\
\hline & & Agriculture & $\begin{array}{c}\text { Chem./ } \\
\text { Chem. } \\
\text { Eng. }\end{array}$ & $\mathrm{FST} / \mathrm{E}$ & $\begin{array}{c}\mathrm{FST} \\
\text { related }\end{array}$ & $\begin{array}{c}\text { Economics/ } \\
\text { Marketing/ } \\
\text { Management }\end{array}$ & Other \\
\hline Research \& development & 28.1 & 34.7 & 42.3 & 30.2 & 21.3 & 16.7 & 34.0 \\
\hline Quality control & 26.1 & 14.7 & 27.9 & 22.4 & 32.0 & 34.5 & 27.8 \\
\hline Production & 19.1 & 10.8 & 13.0 & 20.2 & 18.0 & 15.5 & 10.3 \\
\hline Logistics/distribution & 1.6 & 0.8 & 0.5 & 2.0 & 1.6 & 0.0 & 2.1 \\
\hline Other & 10.8 & 15.9 & 7.7 & 11.0 & 18.0 & 13.1 & 13.4 \\
\hline Consumer/marketing studies & 3.0 & 2.8 & 0.0 & 2.4 & 0.8 & 11.9 & 2.1 \\
\hline Financial/ administrative & 3.1 & 2.4 & 0.5 & 1.2 & 0.8 & 1.2 & 2.1 \\
\hline Legal/legislative & 1.8 & 5.6 & 2.4 & 6.0 & 0.8 & 2.4 & 1.0 \\
\hline Technical/commercial & 3.5 & 7.2 & 2.9 & 2.7 & 0.8 & 3.6 & 2.1 \\
\hline Environment/safety & 2.9 & 5.2 & 2.9 & 1.8 & 5.7 & 1.2 & 5.2 \\
\hline Total & 100 & 100 & 100 & 100 & 100 & 100 & 100 \\
\hline
\end{tabular}


186 | Giannou et al.

provided food-oriented studies in several countries, and still do. It is interesting to note that a considerable percentage of the respondents continued HE studies during their $1^{\text {st }}$ job and most of them aimed obtain a higher degree. The scientific area of this degree was predominantly the same as the one obtained before entering work, indicating a low mobility among disciplines. The second choice comprised "FST/E" or "Management/Marketing". "Management" and "Safety and Hygiene" were the main fields of extracurricular studies, both before and during $1^{\text {st }}$ placement, followed by other food-related topics. It was evident that university study programmes cannot provide a deep knowledge in all FST disciplines, and professionals select complementary extracurricular courses closely related to their job when starting their career. Also, company training focuses mainly on the same topics. Continuous education is well recognized today, and seems to be adopted by both the employees and the companies.

The field of higher education degrees was found to affect both the area of employment and the sector of activity. In particular, "FST/E" degree offers good options for entering work in the food sector (especially in food production) even if other scientific degrees allow the same. There is, however, a need to compensate for missing knowledge by extracurricular training that is also important to keep practitioners working in the food area up-to-date. Gender, although not the main differentiating factor in higher education studies and extracurricular training, affects the entrance in the job market regarding both area and sector of activity.

\section{Acknowledgements}

This work was funded by the Commission of the European Communities Framework 7 Programme through the project 'TRACK_FAST: Training Requirements and Careers for Knowledge-based Food Science and Technology in Europe' an SP1-Cooperation, Coordination and Support Action, grant agreement number: KBBE 227220. The funders had no role in the details of the study design, data collection analysis and interpretation, writing of the report nor decision to publish.

\section{References}

Auriol, L. (2010). Careers of doctorate holders: Employment and mobility patterns, STI WORKING PAPER 2010/4. Retrieved from www . oecd . org / science / inno / 44893058.pdf

Cyranoski, D., Gilbert, N., Ledford, H., Nayar, A., \& Yahia, M. (2011). The PhD Factory. Nature, 472(7343), 276-279.

Flynn, K., Wahnstrom, E., Popa, M., RuizBejarano, B., \& Quintas, M. A. C. (2013). Ideal skills for european food scientists and technologists: identifying the most desired knowledge, skills and competencies. Innovative Food Science \& Emerging Technologies, 18, 246-255. doi:10.1016/j.ifset.2012. 09.004

Food Drink Europe. (2014). Agriculture and tourism trade unions. european federation of food. Retrieved from www . fooddrinkeurope . eu / uploads / press releases_documents/Final_Report2.pdf

Jassi, S., Hart, L., Bayliss, M., Pappadà, G., Magni, C., \& Ghignoni, E. (2013). Ensuring sustainable employment and competitiveness in the EU Food and Drink Industry: Meeting the challenges of the Labour Market. Technical report, European Federation of Food, Agriculture and Tourism Trade Unions - Project VS/2012/0239.

Mayor, L., Flynn, K., Dermesonluoglu, E., Pittia, P., Baderstedt, E., Ruiz-Bejarano, B., ... Costa, R. (2015). Skill development in food professionals: a european study. European Food Research and Technology, 240(5), 871-884. doi:10.1007/s00217-0142400-Z

Oreopoulou, V., Giannou, V., Lakner, Z., Pittia, P., Mayor, L., Silva, C. L. M., \& Costa, R. (2015). Career path of food science and technology professionals: entry to the world of work. Trends in Food Science \&f Technology, 42(2), 183-192. doi:10.1016/j.tifs. 2014.12.006 
Food Science professionals' qualifications at job entry $\mid 187$

Shewfelt, R. L. (2012). Becoming a food scientist: to graduate school and beyond. Springer Science \& Business Media. 